\title{
Intravenous glucose tolerance in myocardial infarction
}

\author{
Donald Pearson \\ M.D., M.R.C.P. \\ Senior Medical Registrar \\ Liverpool Royal Infirmary
}

\begin{abstract}
Summary
Intravenous glucose tolerance tests were carried ont on forty patients with recent myocardial infarction and thirty-nine matched controls with recent bone injury.

Abnormal results were detected in $77.5 \%$ of cardiac patients and $68 \%$ controls. When tests were repeated after acute stress factors had settled, normal results were obtained in $85 \%$ of thirty-three cardiac subjects and $84 \%$ of thirty-eight controls.

It is concluded that the disturbance of glucose tolerance in myocardial infarction is a non-specific stress effect and should not be regarded as necessarily indicating a latent diabetic tendency.
\end{abstract}

\section{Introduction}

Although the association between diabetes and arterial disease has been recognized for centuries, it is only in recent years that attention has been drawn to the finding of hyperglycaemia and abnormal glucose tolerance in apparently non-diabetic patients with ischaemic heart disease (Goldberger, Alesio \& Woll, 1945; Sowton, 1962; Cohen \& Shafrir, 1965).

Whilst disturbances of glucose tolerance following recent myocardial infarction could be a simple stress effect, there is evidence that persistent abnormalities of glucose tolerance are detectable months later when acute stress factors have settled. The usual conclusion drawn from this is that ischaemic heart disease is associated with a latent diabetic tendency which is of aetiological significance and which is manifested as glucose intolerance during acute illness.

Against this theory are two facts to be considered. Firstly, other stress situations can alter glucose tolerance, including burns (Allison, Hinton \& Chamberlain, 1968; Hinton et al., 1971), war wounds (Howard, 1955), and abdominal surgery (Ross et al., 1966). Secondly, there is the incidence of abnormal glucose tolerance in the normal population which reaches $14.5 \%$ in those over 50 years of age (College of General Practitioners, 1963). Unless it can be proved that myocardial infarction is associated with a higher incidence of glucose intolerance than other forms of tissue damage, and that the incidence of glucose intolerance in the resting state is significantly higher than in the general $\omega$ population, there would not seem to be just cause for $\bar{O}$ implicating carbohydrate intolerance as an aetio- $\frac{3}{3}$ logical factor in ischaemic heart disease.

It was surprising to find no record in the literature of a comparative prospective study of glucose $N$ tolerance in matched groups of patients with myo- os cardial infarction and another unrelated type of $\stackrel{\infty}{\infty}$ tissue damage. The present study was conceived in $ᄋ$ order to investigate this question by carrying out glucose tolerance tests after recent myocardial infarction and repeating the tests on as many patients as possible 6-12 months later. As a control grougs identical tests were carried out on a matched group of recently injured patients with radiological pro@i of bone injury.

\section{Method}

Glucose tolerance was assessed by the rapid intravenous method which is considered more $\stackrel{0}{\not}$ reliable and reproducible than the oral glucose $\stackrel{\mathbb{D}}{\triangle}$ tolerance test (Baird \& Duncan, 1959). Twenty-five grams of glucose $(50 \mathrm{ml}$ of $50 \%$ solution) were injected into an arm vein after obtaining a capillary sample for estimating the fasting blood glucose level. Further capillary samples were obtained from an ear lobe incision, kept moist with a heparin soaked swab, every $10 \mathrm{~min}$ for $1 \mathrm{hr}$.

Blood glucose was estimated on an AutoAnalyzer by a ferricyanide-ferrocyanide reduction method (Hoffman, 1937). On plotting the blood sugar levels in excess of the fasting level against time on semilogarithmic paper, a straight line, or near approximate, was always obtained from which the time taken for the blood sugar level to half its value $\left(T_{t}\right)$ could easily be determined. The result of the intravenous glucose tolerance test was expressed as an Increment Index $(K)$ derived from the formula

$$
K=\frac{\log _{\mathrm{e}} 2}{\mathrm{~T}_{\frac{1}{2}}} \text { (Duncan, 1956) }
$$

Such tests were personally carried out on forty patients with undoubted myocardial infarction and 
TABLE 1.

\begin{tabular}{|c|c|c|c|c|c|c|c|c|c|c|}
\hline & \multirow{3}{*}{ No. } & \multirow{3}{*}{ Sex } & \multirow{2}{*}{\multicolumn{2}{|c|}{ Age }} & \multirow{2}{*}{\multicolumn{2}{|c|}{$\begin{array}{l}\text { Weight } \\
\text { (lb) }\end{array}$}} & \multirow{2}{*}{\multicolumn{2}{|c|}{$\begin{array}{l}\text { Height } \\
\text { (in.) }\end{array}$}} & \multicolumn{2}{|c|}{ Post-ictal times } \\
\hline & & & & & & & & & \multirow{2}{*}{$\begin{array}{l}\text { 1st test } \\
\text { (days) }\end{array}$} & \multirow{2}{*}{$\begin{array}{l}\text { 2nd tes } \\
\text { (months) }\end{array}$} \\
\hline & & & Mean & Range & Mean & Range & Mean & Rànge & & \\
\hline Infarction group & 40 & $\begin{array}{l}25 \mathrm{~m} \\
15 \mathrm{f}\end{array}$ & 53 & $38-75$ & 154 & $90-210$ & $65 \cdot 4$ & $61-70$ & $4 \cdot 8$ & $8 \cdot 7$ \\
\hline Fracture group & 39 & $\begin{array}{l}24 \mathrm{~m} \\
15 \mathrm{f}\end{array}$ & 53 & $32-70$ & 151 & $95-200$ & $64 \cdot 8$ & $60-69$ & $3 \cdot 8$ & $10 \cdot 0$ \\
\hline
\end{tabular}

thirty-nine controls who were all victims of accidents resulting in bone injury. All tests were done within 1-23 days of infarction or injury. No patient in either group gave a past or family history of diabetes. Table 1 shows the age, sex, weight, and height, of the two groups.

Repeat tests were carried out in thirty-three $(82.5 \%)$ coronary group and thirty-eight $(97 \cdot 4 \%)$ controls.

Full clinical details of all patients and blood sugar values are available from the author on request.

\section{Results}

Table 2 shows the Increment Indices ( $K$ values) obtained from six mild diabetics (non-ketotic diabetics on dietary or chlorpropamide therapy) and sixteen normal controls (non-diabetic patients awaiting minor surgical operations).

TABLE 2.

\begin{tabular}{lrccc}
\hline & No. & Range $K$ & Mean $K$ & $\begin{array}{c}\text { Standard } \\
\text { deviation }\end{array}$ \\
\hline Mild diabetics & 6 & $1 \cdot 39-2 \cdot 31$ & $1 \cdot 83$ & 0.32 \\
Normal control & 16 & $2 \cdot 77-4 \cdot 62$ & 3.87 & 0.38 \\
\hline
\end{tabular}

TABLE 3.

\begin{tabular}{lccc}
\hline & \multicolumn{3}{c}{ Intravenous glucose tolerance } \\
\cline { 2 - 4 } & $\begin{array}{c}\text { Normal } \\
\end{array}$ & $\begin{array}{c}\text { Diabetic } \\
K(2 \cdot 77-6 \cdot 93)\end{array}$ & $\begin{array}{c}\text { Intermediate } \\
\end{array}$ \\
\hline $\begin{array}{l}\text { Coronary group } \\
\text { Acute }\end{array}$ & $9(22 \cdot 5 \%)$ & $21(52 \cdot 5 \%)$ & $10(25 \%)$ \\
$\begin{array}{l}\text { After recovery } \\
\text { Fracture group }\end{array}$ & $28(84 \cdot 8 \%)$ & $1(3 \%)$ & $4(12 \cdot 1 \%)$ \\
Acute & $12(30 \%)$ & $22(56 \cdot 4 \%)$ & $5(12 \cdot 6 \%)$ \\
After recovery & $32(84 \cdot 2 \%)$ & $0(0 \%)$ & $6(15 \cdot 8 \%)$ \\
\hline
\end{tabular}

TABle 4. Mean $K$ values in study group and controls

\begin{tabular}{lcc}
\hline Group & Mean $K$ value & Standard deviation \\
\hline Myocardial infarction & & \\
Acute phase & 2.55 & 0.89 \\
After recovery & 3.69 & 0.83 \\
Bone injury & & \\
Acute phase & 2.64 & 0.86 \\
After recovery & 3.55 & 0.53 \\
\hline
\end{tabular}

Table 3 summarizes the results of intravenous glucose tolerance tests in forty patients with recent myocardial infarction and thirty-nine recently injured controls. The table also gives the results obtained when the tests were repeated after recovery.

There were seven patients in the study group who could not be retested, three died from the initial infarct, three refused to attend, and one was a Norwegian who returned home. The initial $K$ values of these seven patients were normal in five and intermediate in two.

The criteria of normal, intermediate, and diabetic $K$ values are those given by Duncan (1956), and correspond closely to the small number of preliminary tests done in the present study (Table 2).

\section{Discussion}

The results in both groups are comparable, which suggests that glucose tolerance is severely disturbed by the acute stress of myocardial infarction or bone injury to an approximately equal degree, and recovers in both groups if sufficient time elapses.

There is no excess of abnormal glucose intolerance in quiescent ischaemic heart disease to indicate a latent diabetic tendency.

The opposite conclusion reached by other workers (Sowton, 1962; Wahlberg, 1966; Cohen \& Shafrir, 1965) is based upon a supposed excess of glucose intolerance in patients with ischaemic heart disease.

Sowton (1962) found abnormal glucose tolerance in $43 \%$ of thirty patients 6 months after infarction. However, if the usually accepted criterion of normal glucose tolerance, namely 2-hr level less than 120 $\mathrm{mg} / 100 \mathrm{ml}$ (Sharp, 1964), is applied to his results, only $13 \%$ of his cases would be considered abnormal, which is lower than the predicted incidence in the general population (College of General Practitioners, 1963).

Wahlberg (1966) admitted the difficulty of selecting controls and made no attempt to measure nonspecific stress factors. He found abnormal intravenous glucose tolerance in $60 \%$ of 190 patients after the first infarction and $53 \%$ of 160 after multiple infarcts. His results are unusual in that no alteration of glucose tolerance was noticed whether 
tests were carried out 3-7 days or 3-6 weeks after the attack. This result is unusual as in all other studies, including the present, the disturbance of glucose tolerance is approximately inversely related to the time lapse between infarction and the glucose tolerance test (Dunnigan \& Sawyers, 1965; Datey \& Nanda, 1967).

Cohen \& Shafrir's (1965) finding of glucose intolerance in $77 \%$ of thirty-three patients within 3 weeks of infarction accords with the results of the present study. They repeated oral glucose tolerance tests on eight patients 1 year later and found six abnormal results. They concluded that a latent diabetic tendency was the most likely explanation of these findings, but as no comparable control group was studied there is no reason to suppose that similar findings would not have been obtained from thirty-three burned or injured subjects.

The mechanism by which glucose tolerance is disturbed is uncertain, but excessive catecholamine secretion is a known feature of myocardial infarction (Shillingford \& Thomas, 1967), and it has been shown that diabetic glucose tolerance curves can be produced in normal subjects by catecholamine stimulation (Amatuzio et al., 1954). The prolonged metabolic disturbance following cardiac infarction is sufficient to depress glucose tolerance for some months (Datey \& Nanda, 1967), and the results of tests in coronary disease must allow for this disturbance to settle and be interpreted with care in view of the uncertain significance of minor deviations from the so-called normal glucose tolerance curve.

\section{Acknowledgments}

This paper is a summary of part of an M.D. thesis (University of Liverpool 1969).

I am grateful to Dr A. J. Robertson for his helpful critical advice in the preparation of this paper.

\section{References}

Allison, S.P., Hinton, P. \& Chamberlain, M.J. (1968) Intravenous glucose tolerance, insulin and free fatty-acid levels in burned patients. Lancet, ii, 1113.
Amatuzio, D.S., Alvin, L., Schultz, M.J., Vanderbilt E.D.R. \& NesBiTT, S. (1954) The effects of epinephrine insulin and hyperthyroidism on the rapid intravenouse glucose tolerance test. Journal Clinical Investigation, 33, $97 .$.

BAIRD, J.D. \& DUNCAN, L.J.P. (1959) The glucose tolerance test. Postgraduate Medical Journal, 35, 308.

Cohen, A.M. \& Shafrir, E. (1965) Carbohydrate metabolism in myocardial infarction. Diabetes, $14,84$.

College of General Practitioners Working Party (1963) Glucose tolerance and glycosuria in the general population. British Medical Journal, 2, 655.

DATEY, K.K. \& NANDA, N.C. (1967) Hyperglycaemia afteracute myocardial infarction. New England Journal of Medi-O cine, 276, 262.

DUNCAN, L.J.P. (1956) The intravenous glucose tolerance test. Quarlerly Journal of Experimental Physiology, 41, 85-

Dunnigan, M.G., Sawyers, J.D. \& MCNaIR, D. (1967) Relationship of glucose tolerance to time from myocardiaF. infarction. Quarterly Journal Medicine, 36, 609.

Goldberger, E., Alesio, J. \& Woll, F. (1945) The significance of hyperglycaemia in myocardial infarction. New. York State Journal of Medicine, 45, 391.

Hinton, P., Allison, S.P., Littlejohn, S. \& Lloyd, J. (1971) Insulin and glucose to reduce catabolic response? to injury in burned patients. Lancet, i, 767.

HoFFMAN, W.S. (1937) A rapid photoelectric method for then detection of glucose in blood and urine. Journal of Bio-O logical Chemistry, 120, 51.

HowARD, J.M.H. (1955) Studies of the absorption agdmetabolism of glucose following injury. Annals of Surgegy, 141, 321.

Ross, H., Johnston, I.D.J., Welborn, T.A. \& WRIGHT, A.D. (1966) Effects of abdominal operations on glucose tolerance and serum levels of insulin, growth hormone and hydrocortisone. Lancet, ii, 563.

SharP, C.L. (1964) Diabetes survey in Bedford 1962. Proceed-命 ings of the Royal Society of Medicine, 57, 193.

Shillingford, J.F. \& Thomas, M. (1967) Cardiovascularo and pulmonary changes in patients with myocardial infarction. American Journal of Cardiology, 20, 484.

Sowton, E. (1962) Cardiac infarction and the glucose: tolerance test. British Medical Journal, 1, 84.

WAHLBERG, F. (1966) Intravenous glucose tolerance tests in:myocardial infarction, angina pectoris and intermittent claudication. Acta medica Scandinavica, 180, Suppl. 453. 